\title{
Catalytic Vapor Decomposition of Methane over Nickle Catalyst: Growth Rate and the Corresponding Microstructures of Carbon Nanofibers
}

\author{
Zhi-Jun SuI ${ }^{1}$, Yun-Fei SuN ${ }^{1}$, Jing-Hong ZHOU ${ }^{1}$, \\ Ping $\mathrm{LI}^{1}$, De $\mathrm{CHEN}^{2}$ and Xing-Gui ZHOU ${ }^{1}$ \\ ${ }^{1}$ State Key Laboratory of Chemical Engineering, \\ East China University of Science and Technology, \\ 130 Meilong Road, Shanghai 200237, People's Republic of China \\ ${ }^{2}$ Department of Chemical Engineering, \\ Norwegian University of Science and Technology, \\ N-7491 Trondheim, Norway
}

Keywords: Carbon Nanofibers, Growth Rate, Deactivation, Crystal Size, Microstructure

\begin{abstract}
Time-resolved intrinsic reaction rate of catalytic vapor deposition of methane into carbon nanofibers (CNFs) and hydrogen on supported $\mathrm{Ni}$ catalysts was determined under different reaction temperatures $(\mathbf{7 7 3 - 9 7 3 ~} \mathrm{K})$ and feed compositions $\left(P_{\mathrm{H}_{2}}=0-0.29 \mathrm{~atm}, P_{\mathrm{CH}_{4}}=0.28-0.71 \mathrm{~atm}\right)$ and the microstructure of the produced CNFs was characterized by Raman and TEM. The results showed that, increasing the reaction temperature, methane partial pressure and decreasing hydrogen partial pressure increased the initial reaction rate but generally led to fast catalyst deactivation. A high carbon yield per unit catalyst was obtained as a compromise between initial reaction rate and catalyst deactivation rate. The microstructures of the produced CNFs had a close relationship with the initial reaction rate. The $\mathrm{CNF}$ s produced with high initial rate tended to have a small angle between the graphene layers and the growth axis, thin diameter and a hollow core. This phenomenon can be used for monitoring and controlling the CNFs synthesis process.
\end{abstract}

\section{Introduction}

The history of carbon nanofibers (CNFs) can be traced back to 1889 when the method for synthesis of filamentous carbon by hydrolysis of a mixture of methane and hydrogen in an iron crucible was reported (Ermakova et al., 2001). Carbon nanofibers (CNFs) have unique chemical stability, electrical conductivity, mechanical strength and textural/surface properties (De Jong and Geus, 2000), which make them good candidates for absorbents and catalysts and therefore are the subject of numerous studies especially in the latest few decades. Possible use of carbon nanofibers in super capacitor or fuel cell as part of the electrodes is also a hotspot of research (Xing, 2004).

Catalytic decomposition of methane over Ni catalysts is an effective method for CNFs synthesis and also an alternative route of hydrogen production from natural gas (Takenaka et al., 2002, 2003a, 2003b). This reaction is moderately endothermic:

$$
\mathrm{CH}_{4} \rightarrow \mathrm{C}+2 \mathrm{H}_{2}, \Delta H_{298 \mathrm{~K}}=74.52 \mathrm{~kJ} / \mathrm{mol}
$$

This reaction is also of research interest for inhibition of

Received on July 3, 2008; accepted on May 20, 2009. Correspondence concerning this article should be addressed to X.-G. Zhou (E-mail address: xgzhou@ecust.edu.cn).

Presented at ISCRE 20 in Kyoto, September, 2008. carbon growth in steam or dry reforming of methane process. Comprehensive studies (Chen et al., 2005; Suelves et al., 2005; Lazaro et al., 2007; Biris et al., 2008) have been conducted for many years to elucidate the effect of catalyst particle size and operating variables, such as temperature and feed concentration, on the carbon growth rate and microstructure of the CNFs. Information compiled from these experiments reveals that the growth of CNFs is a complex process, and all the variables can alter the CNFs structure. Despite the large number of publications devoted to the mechanism of carbon nucleation and growth, up to now few researches have been conducted to investigate the changes of intrinsic reaction rate and microstructure with growth condition, which are needed in process development and design for large scale production.

In this paper, CNFs were grown on $\mathrm{Ni}(20 \%) / \gamma$ $\mathrm{Al}_{2} \mathrm{O}_{3}$ catalyst with different particle sizes and at different temperatures and feed concentrations. The rate of carbon growth was recorded as a function of time and the microstructure of the CNFs was characterized. The relationship between the reaction rate and microstructures of the as grown CNFs is established and the reason account for this relationship is also addressed. 
Table 1 Influence of temperature of nickel oxide calcination on textural parameters of the catalysts

\begin{tabular}{cccc}
\hline $\begin{array}{c}\text { Calcination } \\
\text { temperature } \\
{[\mathrm{K}]}\end{array}$ & $\begin{array}{c}\text { BET surface } \\
\text { area }\left[\mathrm{cm}^{2} / \mathrm{g}\right]\end{array}$ & $\begin{array}{c}\text { Total pore } \\
\text { volume } \\
{\left[\mathrm{cm}^{3} / \mathrm{g}\right]}\end{array}$ & $\begin{array}{c}\text { Micropore } \\
\text { volume } \\
{\left[\mathrm{cm}^{3} / \mathrm{g}\right]}\end{array}$ \\
\hline 773 & 194.4 & 0.36 & 0.007 \\
873 & 171.2 & 0.45 & 0.006 \\
973 & 160.0 & 0.39 & 0.004 \\
\hline
\end{tabular}

\section{Experimental}

The $\mathrm{Ni}(20 \%) / \gamma-\mathrm{Al}_{2} \mathrm{O}_{3}$ catalysts used for direct cracking of methane were synthesized by depositionprecipitation using urea as precipitant. Nickel nitrate and urea were dissolved in water and mixed with an aqueous alumina suspension, which was then heated in a water bath to $363 \mathrm{~K}$. The solution was mechanically agitated at $363 \mathrm{~K}$ for $10 \mathrm{~h}$, and was then filtrated under vacuum. The obtained precipitate was dried overnight in air at $393 \mathrm{~K}$. The catalysts with different Ni particle sizes were obtained by calcinating the precipitate at 773,873 and $973 \mathrm{~K}$ for $3 \mathrm{~h}$.

The specific surface area of the catalysts was characterized by nitrogen adsorption at $77 \mathrm{~K}$ on ASAP 2010 (USA). The X-ray powder diffraction (XRD, Rigaku Corp.) pattern was recorded by D/Max $2550 \mathrm{VB} / \mathrm{PC}$ diffractometer equipped with a $\mathrm{Cu} \mathrm{K} \alpha$ radiation source $(\lambda=0.154056 \mathrm{~nm})$ and operated at a voltage of $40 \mathrm{kV}$ and a current of $100 \mathrm{~mA}$. The crystal size of $\mathrm{Ni}$ was determined by $\mathrm{H}_{2}$ chemisorption at $313 \mathrm{~K}$ on Autochem II 2920 (Micromeritics Instrument Corp.). The reducibility of $\mathrm{NiO}$ was studied by temperature programmed reduction (TPR) on Autochem II 2920 (Micromeritics Instrument Corp.). HRTEM images were obtained by a JEM 2010 electron microscope (JEOL Ltd.). Laser Raman spectra were obtained on an inVia+Reflex spectrometer with an $\mathrm{Ar}+$ tuned at $514 \mathrm{~nm}$ and a delivering power of $1-100 \mathrm{~mW}$ at the sample (Renishaw plc.).

The catalytic vapor deposition process was studied at $823-973 \mathrm{~K}$ and atmospheric pressure, using a quartz tubular reactor of $8 \mathrm{~mm}$ i.d. In each experiment, $0.02 \mathrm{~g} \mathrm{Ni}$ $(20 \%) / \gamma-\mathrm{Al}_{2} \mathrm{O}_{3}$ catalysts, with an average size of $74 \mu \mathrm{m}$ and in the oxide state, were loaded and reduced in situ at $873 \mathrm{~K}$ in a $50 \mathrm{~mol} \% \mathrm{H}_{2} / \mathrm{Ar}$ mixture at a total flowrate of $30 \mathrm{~mL} / \mathrm{min}$. After that, the sample was set to the specified reaction temperature in $\mathrm{Ar}$ and then a feed consisting of $\mathrm{CH}_{4}, \mathrm{H}_{2}$ and $\mathrm{Ar}$ was introduced, the total flow rate of which was $105 \mathrm{~mL} / \mathrm{min}$ for all experiments. Some preliminary tests were also carried out and the results indicated that both internal and external diffusion limits could be ruled out under the reaction conditions used in this article. The concentrations of effluent gases were analyzed by an on-line quadruple mass spectrum (Questor, ABB Corp.). $\mathrm{CH}_{4}, \mathrm{Ar}$ and $\mathrm{H}_{2}$ concentrations were determined at $m / z=16,40$ and 2 and recorded at a time interval of
Table 2 Particle sizes of the catalysts with different calcination temperature and the corresponding yields of CNFs

\begin{tabular}{lccc}
\hline Calcination temperature [K] & 773 & 873 & 973 \\
\hline$D_{\mathrm{Ni}}[\mathrm{nm}]$ & 39.6 & 68.3 & 76.5 \\
CNFs yield [g-c/g-cat] & 5.7 & 6.1 & 4.2 \\
\hline
\end{tabular}

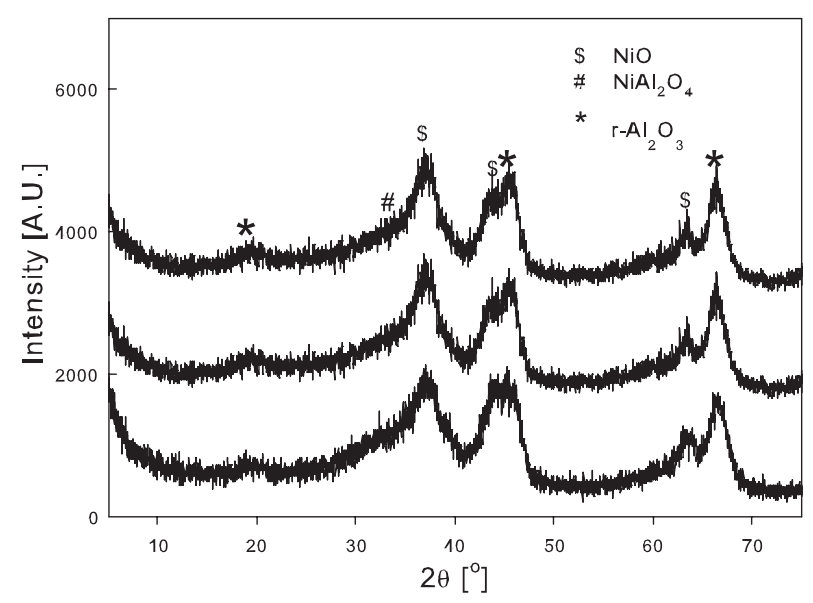

Fig. 1 XRD patterns of catalysts calcined at $773 \mathrm{~K}$ (bottom), $873 \mathrm{~K}$ (middle) and $973 \mathrm{~K}$ (top). Peaks marked with (\$) are characteristic of $\mathrm{NiO}$ structure; peaks marked with (\#) are characteristic of spinel phase.

$0.1 \mathrm{~s}$. The yields of CNFs were calculated from the conversion of methane. After each experiment, the produced CNFs were discharged and weighed. It was found that the difference between the calculated yields and the weighed yield was within $\pm 3 \%$.

\section{Results and Discussion}

\subsection{Influence of calcination temperature}

By applying different temperatures for calcination, one can have different nickel particle sizes. Table 1 shows the decreasing specific surface area of $\mathrm{NiO}$ calcined at 773, 873 and $973 \mathrm{~K}$ respectively and Figure 1 shows the X-ray powder diffraction patterns of the three samples. The average sizes of the NiO crystallites, as calculated by Debye-Scherrer equation, are 11.0, 19.4 and $22.7 \mathrm{~nm}$, respectively. Figure 1 indicates that the crystalline phases of the catalysts are almost identical at these temperatures.

The crystal size of the Ni was characterized by hydrogen chemisorption and the result was shown in Table 2 . The particle size increases with the increase of calcination temperatures, which are consistent with XRD characterization results.

Figure 2 shows the TPR profiles of the calcined samples. A main peak occurs at around $870 \mathrm{~K}$ for the sample calcined at $700 \mathrm{~K}$, corresponding to the reduc- 


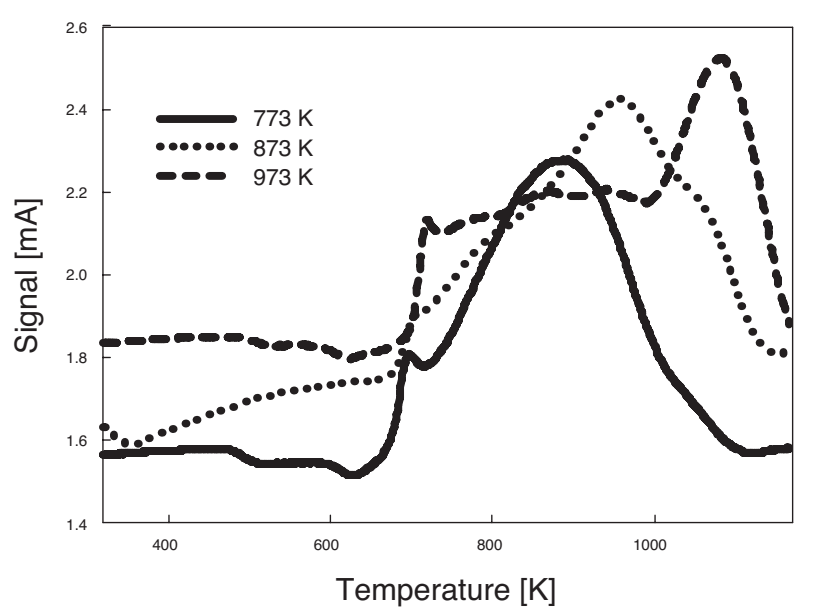

Fig. 2 TPR of catalysts calcined at 773,873 and $973 \mathrm{~K}$ respectively

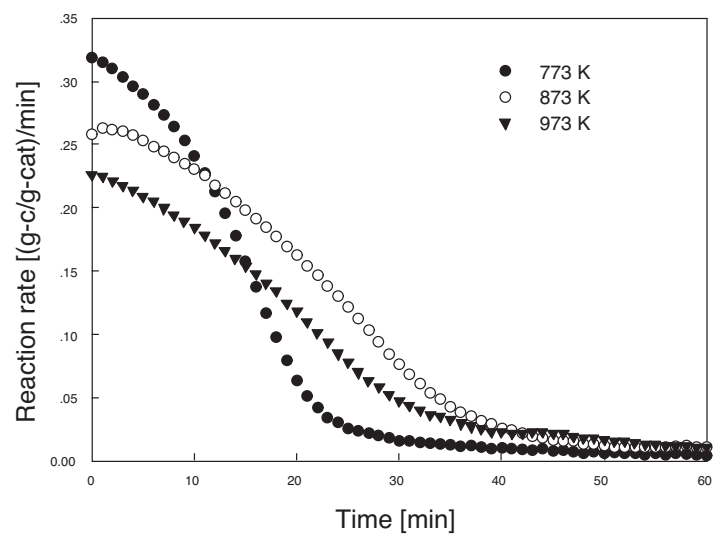

Fig. 3 Influence of the calcination temperature on the rate of decomposition at $873 \mathrm{~K}\left(\mathrm{H}_{2}, 15 \mathrm{~mL} / \mathrm{min}\right.$; Ar, $30 \mathrm{~mL} / \mathrm{min} ; \mathrm{CH}_{4}, 60 \mathrm{~mL} / \mathrm{min}$ )

tion of $\mathrm{NiO}$ particles with weak $\mathrm{NiO}-\gamma-\mathrm{Al}_{2} \mathrm{O}_{3}$ interaction. However, for the sample calcined at $873 \mathrm{~K}$, this peak shifts to $950 \mathrm{~K}$. The peak occurs at around $1073 \mathrm{~K}$ is attributed to the reduction of the $\mathrm{NiAl}_{2} \mathrm{O}_{4}$ phase.

The rates of methane decomposition on catalysts calcinated at different temperatures are presented in Figure 3 and the unit yields of the CNFs are 5.7, 6.1 and $4.2 \mathrm{~g}$-c/g-cat respectively. Figure 3 shows that the calcination temperature has significant effects on the CNFs growth rate, in terms of the rate of initial carbon growth and the rate of catalyst deactivation. Wang et al. (2002) reported that the optimal crystal size of $\mathrm{Ni}$ was around $30 \mathrm{~nm}$ and smaller crystals gave lower growth rates because of faster deactivation as a result of higher surface coverage of carbon on the metal surface. Our results indicate that a catalyst with a smaller particle size has a higher initial carbon growth rate but also undergoes a faster deactivation, thus leading a low carbon yield. Since catalyst calcined at $873 \mathrm{~K}$ has the highest yield in the three sam-
Table 3 The yields of CNFs under different reaction temperature

\begin{tabular}{cc}
\hline Calcination temperature $[\mathrm{K}]$ & CNFs yields [g-c/g-cat] \\
\hline 773 & 1.65 \\
823 & 4.94 \\
873 & 7.97 \\
898 & 8.30 \\
923 & 10.28 \\
948 & 5.91 \\
973 & 5.19 \\
\hline
\end{tabular}

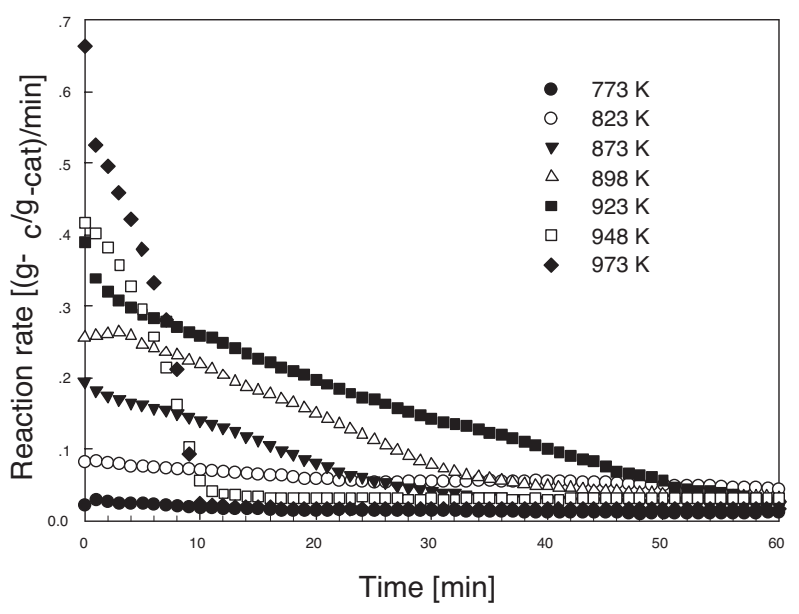

Fig. 4 Influence of temperature on the reaction rate $\left(\mathrm{H}_{2}\right.$, $15 \mathrm{~mL} / \mathrm{min}$; Ar, $30 \mathrm{~mL} / \mathrm{min}$; $\mathrm{CH}_{4}, 60 \mathrm{~mL} / \mathrm{min}$ )

ples, further kinetic experiments are carried out on this catalyst.

\subsection{Influence of reaction temperature}

The influences of reaction temperature on the carbon growth rate are shown in Figure 4 The reaction becomes prominent above $823 \mathrm{~K}$. The initial CNFs growth is faster at higher temperature and the deactivation is also faster as a result of rapid formation of encapsulating carbon. Table 3 shows the yields of CNFs produced at different reaction temperatures. The highest yield was obtained at $923 \mathrm{~K}$.

The reaction temperature also influences the graphitic order of the CNFs. Figure 5 shows the Raman spectrum of the CNFs samples produced at 823, 873 and $973 \mathrm{~K}$, respectively. The graphitic order of CNFs can be deduced from the observation of D- and G-bands. The existing band at $1580 \mathrm{~cm}^{-1}, \mathrm{G}$ mode, is assigned to the in-plane displacement in the hexagonal graphite layer, whereas the bands at $1345 \mathrm{~cm}^{-1}$, D mode, is assigned to the disorder in the graphitic structure. The integral intensity ratio, $I_{\mathrm{D}} / I_{\mathrm{G}}$, is inversely proportional to the microcrystalline planar size $L_{\mathrm{a}}$. Low $I_{\mathrm{D}} / I_{\mathrm{G}}$ ratio reflects high graphitization order.

The intensities of D mode and G mode are obtained 
Table 4 Graphitic order of CNFs produced at 823, 873 and $973 \mathrm{~K}$ respectively

\begin{tabular}{rcc}
\hline Formation conditions & $I_{\mathrm{D}} / I_{\mathrm{G}}$ & Fitting residual error \\
\hline $823 \mathrm{~K}, P_{\mathrm{H}_{2}}=0.14 \mathrm{~atm}$, & 3.62 & 0.22 \\
$P_{\mathrm{CH}_{4}}=0.57 \mathrm{~atm}$ & & \\
$873 \mathrm{~K}, P_{\mathrm{H}_{2}}=0.14 \mathrm{~atm}$, & 3.27 & 0.66 \\
$P_{\mathrm{CH}_{4}}=0.57 \mathrm{~atm}$ & & \\
$973 \mathrm{~K}, P_{\mathrm{H}_{2}}=0.14 \mathrm{~atm}$, & 2.51 & 0.48 \\
$P_{\mathrm{CH}_{4}}=0.57 \mathrm{~atm}$ & & \\
\hline
\end{tabular}

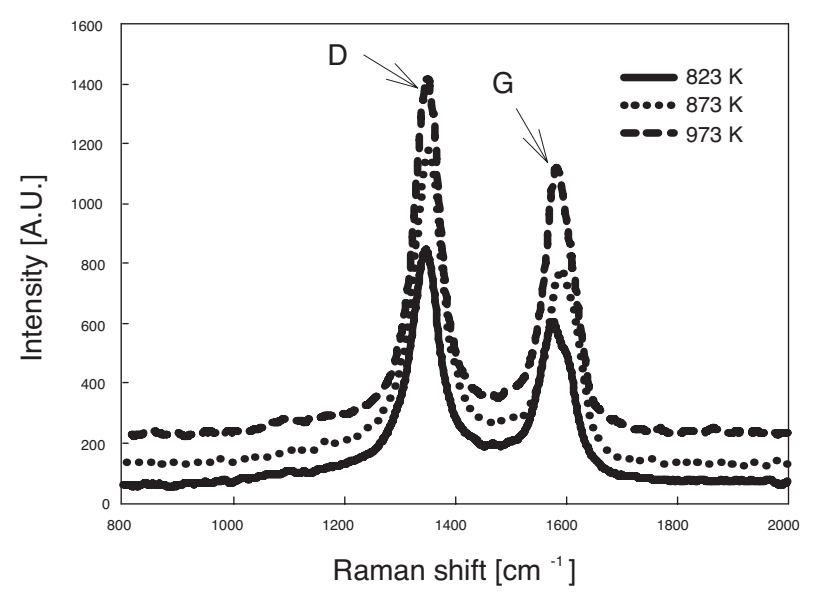

Fig. 5 Raman spectra of CNFs produced at 823, 873 and $973 \mathrm{~K}$ respectively

by fitting the Raman spectrum and results are listed in Table 4.

All the samples have high $G$ bond intensity which means that they all have graphitic structures. Moreover, the CNFs grown at higher temperatures have more ordered graphite structure, which is in accordance with previous observations (Hernadi et al., 2000; Singh et al., 2003).

\subsection{Influence of methane partial pressure}

The effect of methane partial pressure $\left(P_{\mathrm{CH}_{4}}\right)$ on the rate of CNFs growth at a given $P_{\mathrm{H}_{2}}(0.14$ atm) was studied at 873 and $923 \mathrm{~K}$ and the results are shown in Figure 6, from which we can see that the CNFs growth rate is continuously decreasing and holds at a residual constant value. The initial rate of CNFs formation is fast at high $P_{\mathrm{CH}_{4}}$, and the deactivation of the catalyst is also high. High $P_{\mathrm{CH}_{4}}$ will increase the rate of surface reaction then lead to a boost in the diffusion-precipitation process through the Ni crystallites, which in turn causes the increase in the initial reaction rate. However, the higher the $P_{\mathrm{CH}_{4}}$, the higher the rate of formation of the polymeric species which can encapsulate and deactivate the surface of the Ni crystallites. Also it is interesting to note that the residual rate of carbon growth, which is relatively small when compared with the initial growth rate, is larger at
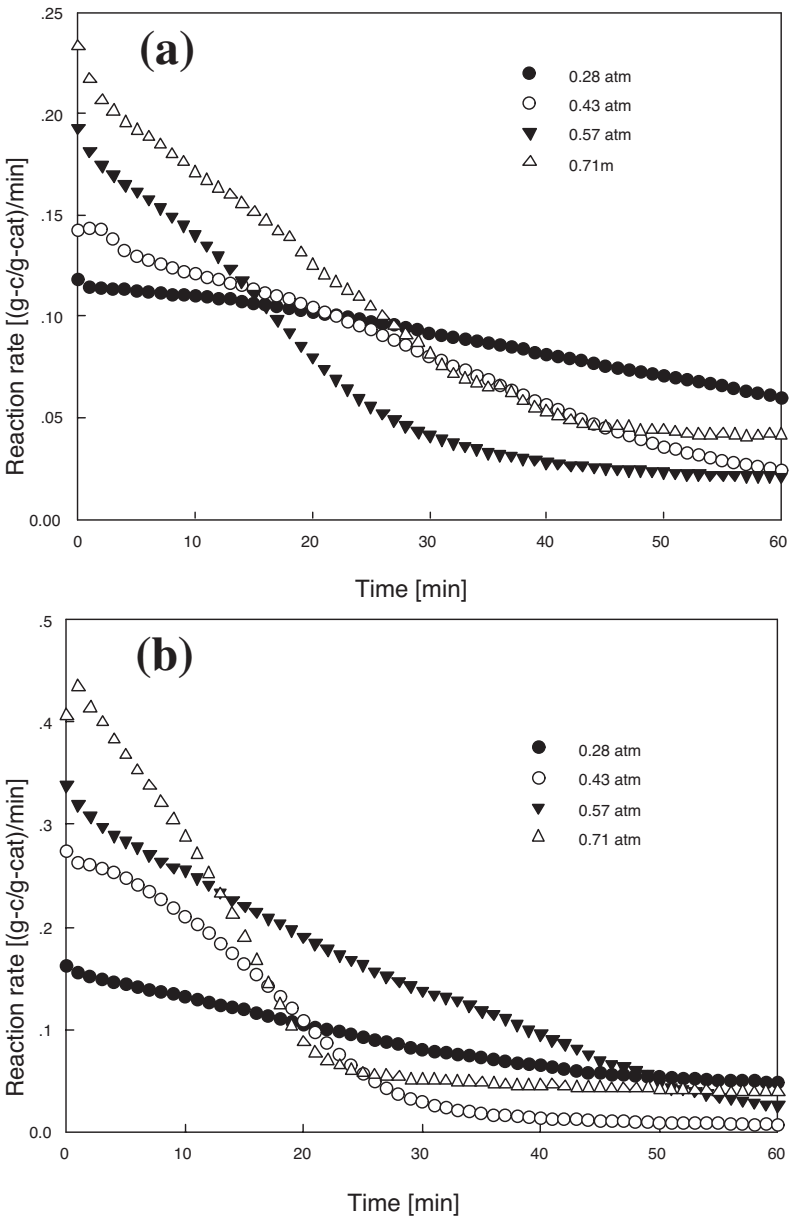

Fig. 6 The effect of $P_{\mathrm{CH}_{4}}$ on carbon growth rate at $873 \mathrm{~K}$ (up) and $923 \mathrm{~K}$ (down) at $P_{\mathrm{H}_{2}}=0.14 \mathrm{~atm}$

lower $P_{\mathrm{CH}_{4}}$. Perhaps this is because the encapsulating carbon formed on the catalyst is not tightly compacted when the initial carbon growth rate is low, which makes it easier for methane to diffuse through the encapsulating carbon layer.

\subsection{Influence of hydrogen partial pressure}

The role of hydrogen has been studied extensively in both the CNF and CNT synthesis researches. The presence of hydrogen has been found to both accelerate (Pinheiro et al., 2000; Venegoni et al., 2002; Neumayer and Haubner, 2004) and suppress (Singh et al., 2003) the formation of CNFs.

Figure 7 shows the effect of $P_{\mathrm{H}_{2}}$ on the carbon growth rate at $P_{\mathrm{CH}_{4}}$ of 0.57 atm and 873 or $923 \mathrm{~K}$. Increasing the $P_{\mathrm{H}_{2}}$ will decrease the rate of carbon growth and also the rate of deactivation remarkably, resulting a net increasing in the yield of CNFs. For example, at $873 \mathrm{~K}$, the yield is increased from $4.81 \mathrm{~g}$-c/g-cat to $11.69 \mathrm{~g}$-c/g-cat when $P_{\mathrm{H}_{2}}$ is increased from zero to 0.29 atm. The effect of $P_{\mathrm{H}_{2}}$ on the formation of CNFs is not straightforward. Higher $P_{\mathrm{H}_{2}}$ can enhance hydrogen adsorption, reduce methane adsorption and suppress 

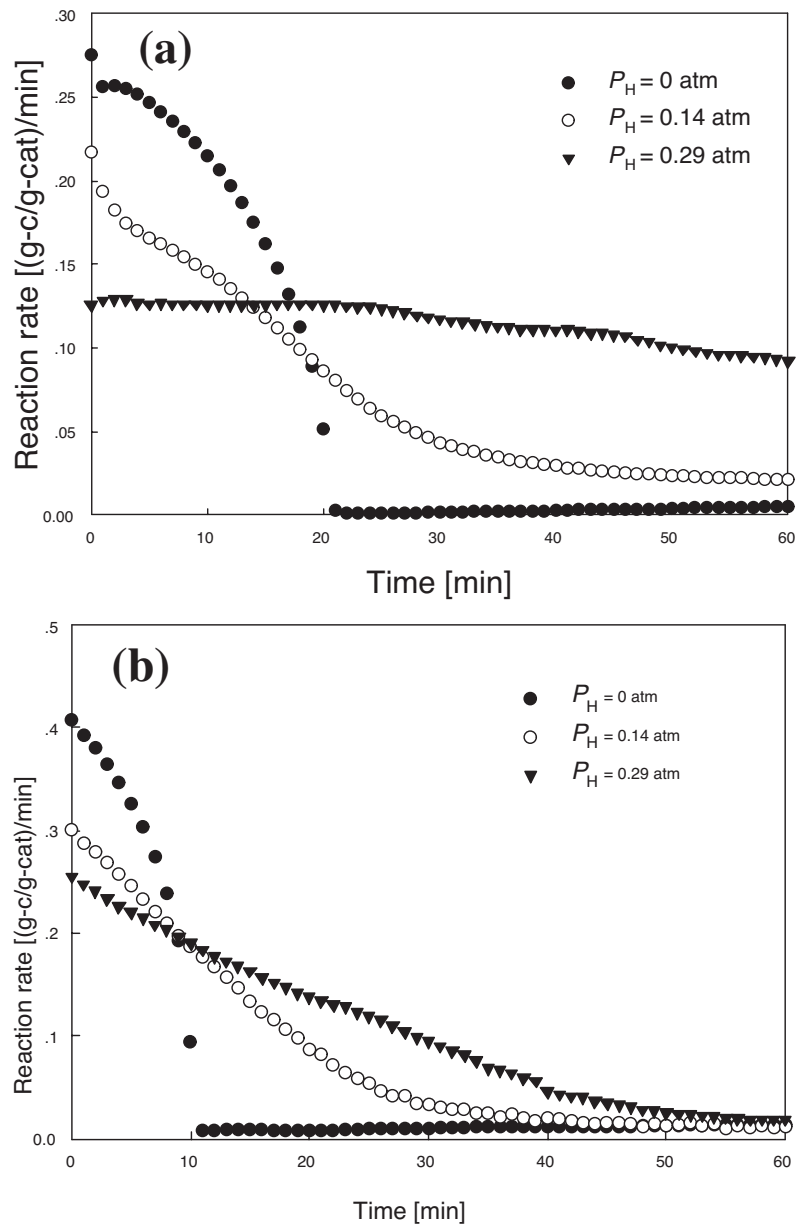

Fig. 7 The effect of $P_{\mathrm{H}_{2}}$ on CNFs growth rate at $873 \mathrm{~K}$ (up) and $923 \mathrm{~K}$ (down) at $P_{\mathrm{CH}_{4}}=0.57 \mathrm{~atm}$

methane dissociation, which decreases the rate of carbon growth. On the other hand, higher $P_{\mathrm{H}_{2}}$ will also promote the gasification of the newly formed surface carbon, resulting in a low surface carbon coverage. Furthermore, the increased site coverage by hydrogen will suppress the polymerization of carbon and thus the formation of encapsulating carbon. These two factors account for the decreased rate of deactivation.

Figure 8 shows the Raman spectra of the CNFs samples produced at $873 \mathrm{~K}$ with different values of $P_{\mathrm{H}_{2}}$. The $I_{\mathrm{D}} / I_{\mathrm{G}}$ values obtained by fitting the Raman spectra are listed in Table 5. The results indicate that the CNFs produced without additional hydrogen have more ordered structure. Though inducing additional $\mathrm{H}_{2}$ will decrease the initial rate of CNFs growth, it will increase the averaged rate of carbon growth, yielding a less ordered lattice structure. On the other hand, higher $\mathrm{H}_{2}$ concentration will help to reconstruct the precipitated carbon by gasification of the unsaturated and highly active carbon atoms.
Table 5 Graphitization degree of CNFs produced at different $P_{\mathrm{H}_{2}}$

\begin{tabular}{rcc}
\hline Formation conditions & $I_{\mathrm{D}} / I_{\mathrm{G}}$ & Fitting residual error \\
\hline $873 \mathrm{~K}, P_{\mathrm{H}_{2}}=0.00 \mathrm{~atm}$, & 1.90 & 0.27 \\
$P_{\mathrm{CH}_{4}}=0.57 \mathrm{~atm}$ & & \\
$873 \mathrm{~K}, P_{\mathrm{H}_{2}}=0.14 \mathrm{~atm}$, & 3.27 & 0.66 \\
$P_{\mathrm{CH}_{4}}=0.57 \mathrm{~atm}$ & & \\
$873 \mathrm{~K}, P_{\mathrm{H}_{2}}=0.29 \mathrm{~atm}$, & 2.62 & 0.21 \\
$P_{\mathrm{CH}_{4}}=0.57 \mathrm{~atm}$ & & \\
\hline
\end{tabular}

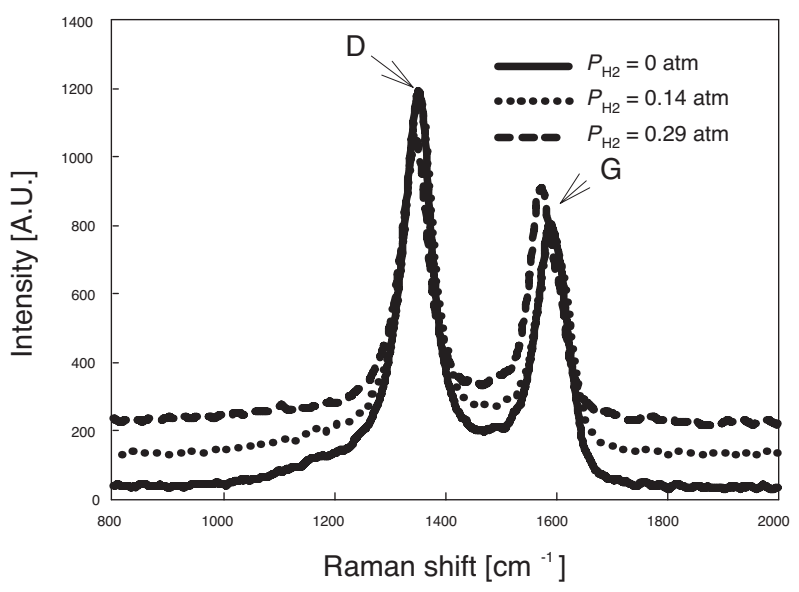

Fig. 8 Raman spectra of CNFs produced at $P_{\mathrm{H}_{2}}=0,0.14$, and $0.29 \mathrm{~atm}$, respectively

\subsection{Relationship between initial reaction rate and microstructure of CNFs}

The morphology of CNFs and their diameter distribution were studied by both high and low-resolution TEM. Figure 9 shows the microstructure of the CNFs produced on $\mathrm{Ni} / \gamma-\mathrm{Al}_{2} \mathrm{O}_{3}$ at $823,873,923$ and $973 \mathrm{~K}$ respectively and Figure 10 shows the microstructure of the CNFs produced on $\mathrm{Ni} / \gamma-\mathrm{Al}_{2} \mathrm{O}_{3}$ at $873 \mathrm{~K}$ but at different values of $P_{\mathrm{H}_{2}}$. All the samples have a typical fishbone structure regardless of the growth conditions, but the angle between the graphite planes and axis of the fiber is very different from each other, as seen in Table 6.

From the TEM images shown in Figures 9 and 10, it is interesting to find that the angle between graphite planes and axis of the fiber is related to the initial reaction rate, as listed in Table 6. The CNFs produced with a higher initial formation rate has a smaller angle, just as Figure 11 shows.

Another microstructural feature should also be noticed. The CNFs produced with a low initial reaction rate tend to have a solid core, as shown in Figure 9(a) and Figure 10(c), whereas the CNFs produced with high initial reaction rate have "hollows" cores, as can be seen from Figures 9(c), (d) and 10(a). This type of "hollow" CNFs was called "cup-stacked-type" CNFs by Endo et 
Table 6 The angles between the graphite planes and axis of the fiber of samples produced at different conditions

\begin{tabular}{|c|c|c|}
\hline Reaction condition & $\begin{array}{c}R_{C, \max } \\
{[(\text { g-c } / \text { g-cat }) / \min ]}\end{array}$ & Angle $\left[{ }^{\circ}\right]$ \\
\hline $823 \mathrm{~K} \backslash P_{\mathrm{H}_{2}}=0.14 \mathrm{~atm}$ & 0.08 & 42.10 \\
\hline $873 \mathrm{~K} \backslash P_{\mathrm{H}_{2}}=0.29 \mathrm{~atm}$ & 0.13 & 34.46 \\
\hline $873 \mathrm{~K} \backslash P_{\mathrm{H}_{2}}=0.14 \mathrm{~atm}$ & 0.18 & 25.66 \\
\hline $873 \mathrm{~K} \backslash P_{\mathrm{H}_{2}}=0.00 \mathrm{~atm}$ & 0.28 & 19.69 \\
\hline $923 \mathrm{~K} \backslash P_{\mathrm{H}_{2}}=0.14 \mathrm{~atm}$ & 0.39 & 7.50 \\
\hline $973 \mathrm{~K} \backslash P_{\mathrm{H}_{2}}=0.14 \mathrm{~atm}$ & 0.66 & 6.64 \\
\hline
\end{tabular}
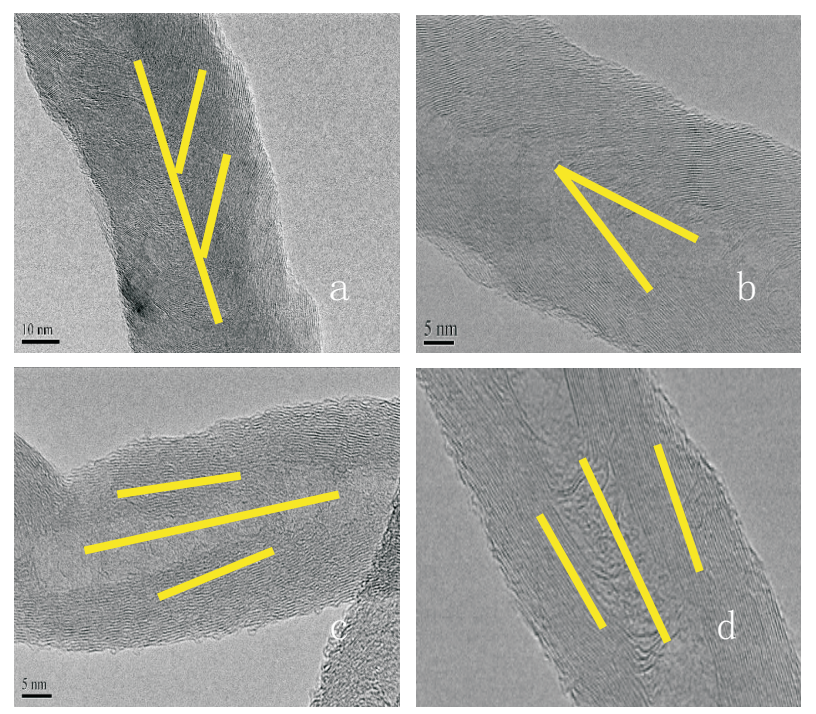

Fig. 9 HRTEM pictures of CNFs produced at (a) $823 \mathrm{~K}$, (b) $873 \mathrm{~K}$, (c) $923 \mathrm{~K}$ and (d) $973 \mathrm{~K} ; P_{\mathrm{CH}_{4}}=0.57 \mathrm{~atm}$, $P_{\mathrm{H}_{2}}=0.14$ atm

\section{al. (2002).}

Figure 12 shows the morphology of CNFs produced at different $P_{\mathrm{H}_{2}}$. The diameter distribution, which was determined by counting more than $100 \mathrm{CNFs}$ on the TEM images, is also presented as insets. It is also interesting to note that the size of the CNFs increases with the $P_{\mathrm{H}_{2}}$ increasing.

It has been accepted that the microstructure of the CNFs was largely determined by the morphology and structure of Ni. Zaikovskii et al. (2001) reported that the state (morphology and structure) of Ni for CNFs growth determined the microstructure of CNFs. Ducati et al. (2004) also found that Ni particle could be altered by increasing reaction temperature from 723 to $923 \mathrm{~K}$ and thus the wall and bamboo like intersects be changed. Further, the Ni particle could transform its shape during the reaction. Helveg and coworkers (Helveg et al., 2004) found the periodic elongation/contraction of $\mathrm{Ni}$ when carbon deposits and grows on $\mathrm{Ni}$ surface. The initial shape of $\mathrm{Ni}$ transforms into a highly elongated shape, and the elongation of the Ni particle appears to be correlated with the
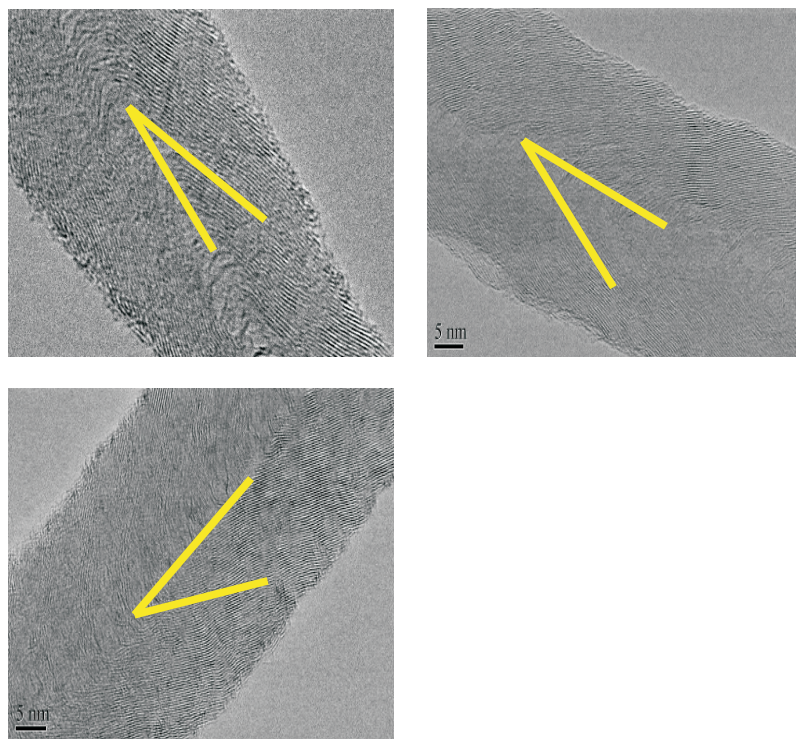

Fig. 10 HRTEM pictures of CNFs produced at (a) $P_{\mathrm{H}_{2}}=$ $0.00 \mathrm{~atm}$, (b) $P_{\mathrm{H}_{2}}=0.14$ atm and (c) $P_{\mathrm{H}_{2}}=$ $0.29 \mathrm{~atm}$

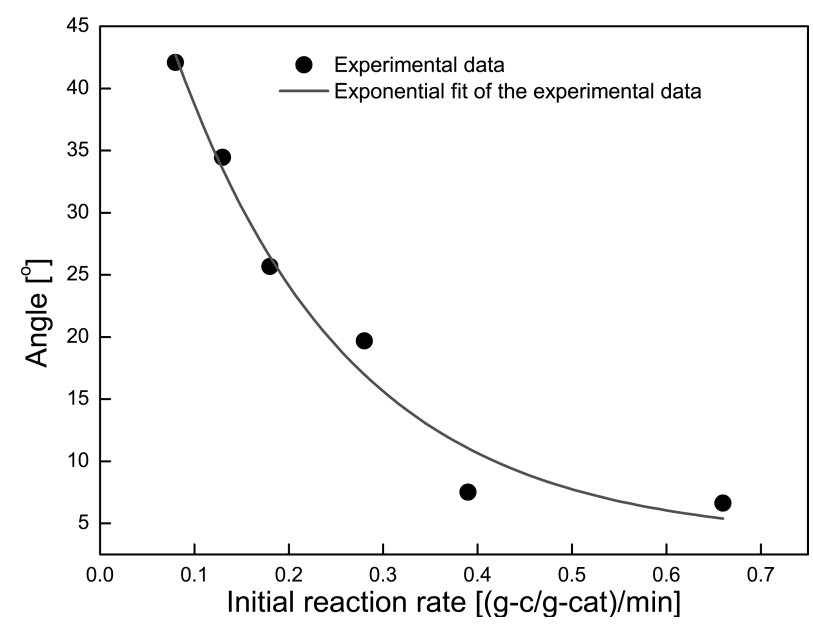

Fig. 11 The relationship between the microstructure and initial growth rate of CNFs

formation of more graphite sheets at the graphite-Ni interface with their basal (002) planes oriented parallel to the Ni surface. The elongation of the Ni nano-crystal continues until it achieves an aspect ratio (length/width) of up to 4 , before it abruptly contracts to a spherical shape within less than $0.5 \mathrm{~s}$. The contraction is attributed to the fact that the increase in the Ni surface energy can no longer be compensated for by the energy gained when binding the graphitic fiber to the Ni surface.

The above findings can be used to illustrate the relationship between the microstructures of the CNFs and the initial reaction rate. When the initial reaction rate is high, more carbon atoms will dissolve into the Ni particles, the elongation effect of the particle is remarkable and the 
(a)

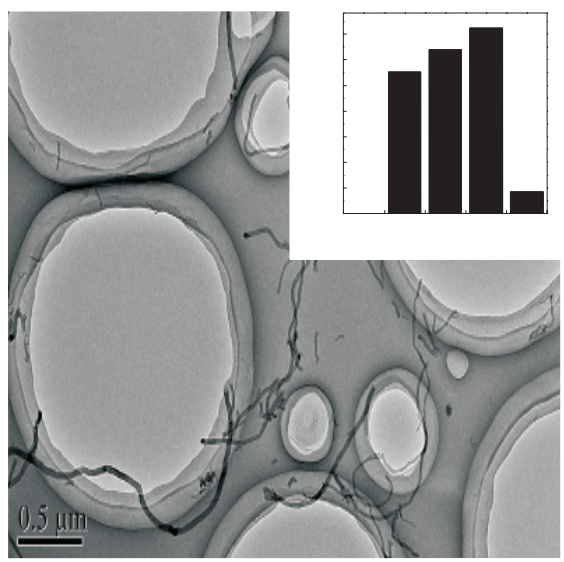

(c)

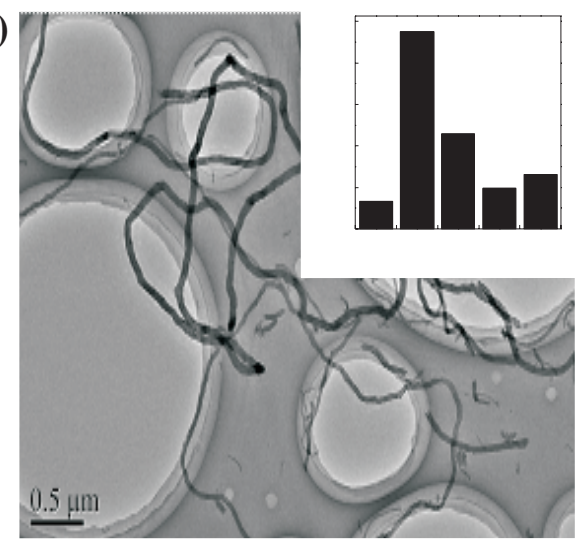

(b)

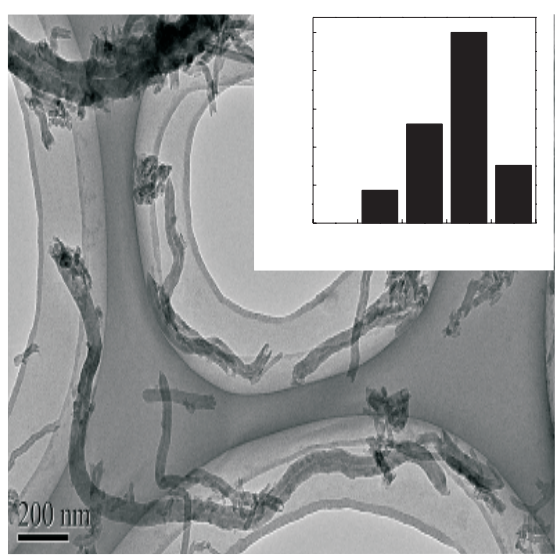

Fig. 12 TEM pictures of CNFs produced at (a) $P_{\mathrm{H}_{2}}=0.00 \mathrm{~atm}$, (b) $P_{\mathrm{H}_{2}}=0.14$ atm and (c) $P_{\mathrm{H}_{2}}=0.29 \mathrm{~atm}$

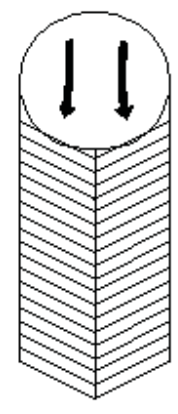

Low rate

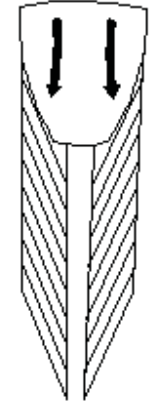

Midium rate

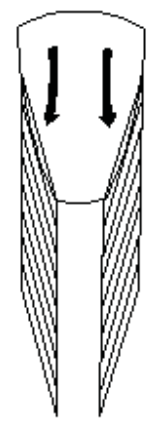

High rate
Fig. 13 The effect of initial reaction rate on structure of $\mathrm{Ni}$

particle will have a high aspect ratio. Thus, the Ni particles which have different initial reaction rates of methane decomposition have different shapes, as depicted in Figure 13. In a Ni particle with high aspect ratio, carbon atoms tend to precipitate at the side walls where the diffusion path is shorter than that at the bottom of the particle and the produced CNFs will have small diameters and angles between the graphite layers and the growth axis.
These results imply that the initial reaction rate could be used to predict the microstructures of the produced CNFs, whatever the changing of the initial reaction rate is caused by reaction temperature, feed compositions or other reaction conditions. This conclusion is of practical significance for monitoring and controlling the CNFs growth process.

\section{Conclusions}

In this work, the rate of CNFs growth by methane decomposition on supported $\mathrm{Ni}$ catalysts and the microstructure of CNFs were determined. The following conclusions can be drawn from the experiments:

1. Under the reaction conditions used in this work, increasing reaction temperature, methane partial pressure and decreasing hydrogen partial pressure can increase the initial reaction rate.

2. A high initial reaction rate often leads to a fast catalyst deactivation rate and thus high carbon yield per unit catalyst can only be obtained as a compromise between initial reaction rate and catalyst deactivation rate. The highest carbon yield obtained in this work is $11.69 \mathrm{~g} / \mathrm{g}$-cat under the condition: reaction temperature, $873 \mathrm{~K}, P_{\mathrm{H}_{2}}=0.29 \mathrm{~atm}, P_{\mathrm{CH}_{4}}=$ $0.57 \mathrm{~atm}$. 
3. The microstructures of the produced CNFs, e.g. the angles between the graphene layers and growth axis, diameters, etc., vary with the reaction conditions.

4. The microstructures of the produced CNFs have a close relationship with the initial reaction rate. The CNFs produced with high initial rate tend to have small angles and diameters and a hollow core. This phenomenon can be related to the shape of Ni particles developed in the reaction.

\section{Acknowledgments}

This work is supported by NSFC (NO. 20490200), the MOE of China (IRT0721), the Opening Project of State Key Laboratory of Chemical Engineering (SKL-ChE-08C05) and the SAFEA of China (B08021).

\section{Literature Cited}

Biris, A. R., Z. Li, E. Dervishi, D. Lupu, Y. Xu, V. Saini, F. Watanabe and A. S. Biris; "Effect of Hydrogen on the Growth and Morphology of Single Wall Carbon Nanotubes Synthesized on a FeMo/MgO Catalytic System," Phys. Lett. A, 372, 3051-3057 (2008)

Chen, D., K. O. Christensen, E. Ochoa-Fernández, Z. Yu, B. Tøtdal, N. Latorre, A. Monzón and A. Holmen; "Synthesis of Carbon Nanofibers: Effects of Ni Crystal Size during Methane Decomposition," J. Catal., 229, 82-96 (2005)

De Jong, K. and J. Geus; "Carbon Nanofibers: Catalytic Synthesis and Applications," Catal. Rev. Sci. Eng., 42, 481-510 (2000)

Ducati, C., I. Alexandrou, M. Chhowalla, J. Robertson and G. A. J. Amaratunga; "The Role of the Catalytic Particle in the Growth of Carbon Nanotubes by Plasma Enhanced Chemical Vapor Deposition." J. Appl. Phys., 95, 6387-6391 (2004)

Endo, M., Y. A. Kim, T. Hayashi, T. Fukai, K. Oshida, M. Terrones, T. Yanagisawa, S. Higaki and M. S. Dresselhaus; "Structural Characterization of Cup-Stacked-Type Nanofibers with an Entirely Hollow Core," Appl. Phys. Lett., 80, 1267-1269 (2002)

Ermakova, M. A., D. Y. Ermakov, A. L. Chuvilin and G. G. Kuvshinov; "Decomposition of Methane over Iron Catalysts at the Range of Moderate Temperatures: The Influence of Structure of the Catalytic Systems and the Reaction Conditions on the Yield of Carbon and Morphology of Carbon Filaments," J. Catal., 201, 183-197 (2001)

Helveg, S., C. López-Cartes, J. Sehested, P. L. Hansen, B. S. Clausen, J. R. Rostrup-Nielsen, F. Abild-Pedersen and J. K. Nørskov; "Atomic-Scale Imaging of Carbon Nanofibre Growth," Nature, 427, 426-429 (2004)
Hernadi, K., A. Fonseca, J. B. Nagy, A. Siska and I. Kiricsi; "Production of Nanotubes by the Catalytic Decomposition of Different CarbonContaining Compounds," Appl. Catal., A, 199, 245-255 (2000)

Lazaro, M. J., Y. Echegoyen, I. Suelves, J. M. Palacios and R. Moliner; "Decomposition of Methane over $\mathrm{Ni}-\mathrm{SiO}_{2}$ and $\mathrm{Ni}-\mathrm{Cu}-\mathrm{SiO}_{2}$ Catalysts: Effect of Catalyst Preparation Method," Appl. Catal., A, 329, 22-29 (2007)

Neumayer, H. and R. Haubner; "Formation of Carbon-Nano-Fibres and Carbon-Nanotubes with a Vertical Flow-Reactor," Diamond Relat. Mater., 13, 1191-1197 (2004)

Pinheiro, P., Schouler, M. C. Schouler, P. Gadelle, M. Mermoux and E. Dooryhée; "Effect of Hydrogen on the Orientation of Carbon Layers in Deposits from the Carbon Monoxide Disproportionation Reaction over $\mathrm{Co} / \mathrm{Al}_{2} \mathrm{O}_{3}$ Catalysts," Carbon, 38, 1469-1479 (2000)

Singh, C., M. S. P. Shaffer and A. H. Windle; "Production of Controlled Architectures of Aligned Carbon Nanotubes by an Injection Chemical Vapour Deposition Method," Carbon, 41, 359-368 (2003)

Suelves, I., M. J. Lázaro, R. Moliner, B. M. Corbella and J. M. Palacios; "Hydrogen Production by Thermo Catalytic Decomposition of Methane on Ni-Based Catalysts: Influence of Operating Conditions on Catalyst Deactivation and Carbon Characteristics," Int. J. Hydrogen Energy, 30, 1555-1567 (2005)

Takenaka, S., H. Ogihara and K. Otsuka; "Structural Change of Ni Species in $\mathrm{Ni} / \mathrm{SiO}_{2}$ Catalyst during Decomposition of Methane," J. Catal., 208, 54-63 (2002)

Takenaka, S., E. Kato, Y. Tomikubo and K. Otsuka; "Structural Change of Ni Species during the Methane Decomposition and the Subsequent Gasification of Deposited Carbon with $\mathrm{CO}_{2}$ over Supported Ni Catalysts," J. Catal., 219, 176-185 (2003a)

Takenaka, S., S. Kobayashi, H. Ogihara and K. Otsuka; "Ni/SiO 2 Catalyst Effective for Methane Decomposition into Hydrogen and Carbon Nanofiber," J. Catal., 217, 79-87 (2003b)

Venegoni, D., P. Serp, R. Feurer, Y. Kihn, C. Vahlas and P. Kalck; "Parametric Study for the Growth of Carbon Nanotubes by Catalytic Chemical Vapor Deposition in a Fluidized Bed Reactor," Carbon, 40, 1799-1807 (2002)

Wang, P., E. Tanabe, K. Ito, J. Jia, H. Morioka, T. Shishido and K. Takehira; "Filamentous Carbon Prepared by the Catalytic Pyrolysis of $\mathrm{CH}_{4}$ on $\mathrm{Ni} / \mathrm{SiO}_{2}$, , Appl. Catal. A, 231, 35-44 (2002)

Xing, Y.; "Synthesis and Electrochemical Characterization of Uniformly-Dispersed High Loading Pt Nanoparticles on Sonochemically-Treated Carbon Nanotubes," J. Phys. Chem. B, 108, 19255-19259 (2004)

Zaikovskii, V. I., V. V. Chesnokov and R. A. Buyanov; "The Relationship between the State of Active Species in a Ni/Al $\mathrm{O}_{3}$ Catalyst and the Mechanism of Growth of Filamentous Carbon," Kinet. Catal., 42, 813-820 (2001) 